\title{
SEMIÓTICA APLICADA AO ESTUDO DA METROPOLIZAÇÃO DO ESPAÇO NO CONTEXTO DA REGIÃO METROPOLITANA DE MANAUS
}

\author{
Semiotics applied to the study of space metropolization: the case of the \\ Metropolitan Region of Manaus
}

\author{
Fredson Bernardino Araújo da Silva \\ Universidade Federal do Amazonas - UFAM \\ fbernardin01997@gmail.com \\ Marcos Castro de Lima \\ Universidade Federal do Amazonas - UFAM \\ castrolmar1@gmail.com
}

\section{Recebido em 13/09/2018 Aceito em 16/11/2020}

RESUMO: A Região Metropolitana de Manaus (RMM) constitui uma realidade jurídica, porém, quanto à expressão socioespacial, ainda se encontra em processo de produção. O recorte desta análise consta da metrópole e do município de Iranduba, na parte sul da região metropolitana. A presente proposta tem o objetivo de compreender o quadro do processo de metropolização do espaço por meio do estudo da semiótica. Trata-se de uma análise geográfica, ou seja, do discurso que pretende legitimar os processos socioespaciais. Considera-se a importância dos agentes modeladores do espaço urbano e metropolitano. Observou-se que na área de estudo a metropolização do espaço se revela por meio do discurso produzido, evocando uma dimensão de modernidade e vantagens de se integrar a esses novos espaços. Dessa dinâmica, tem-se como principal agente o Estado (na Amazônia Ocidental), além da participação dos promotores imobiliários na publicidade.

Palavras-chave: Metropolização do espaço; Região Metropolitana de Manaus; Semiótica.

\begin{abstract}
The Metropolitan Region of Manaus (RMM) is a legal reality, however, in terms of sociospatial expression, it is still in the production process. This analysis is part of the metropolis and the municipality of Iranduba, in the southern part of the metropolitan region. This proposal aims to understand the framework of the process of metropolitan space through the study of semiotics. It is a geographic analysis, that is, the discourse that aims to legitimize the sociospatial processes. The importance of the modeling agents of the urban and metropolitan space is considered. It was observed that in the study area the metropolization of space is revealed through the discourse produced, evoking a dimension of modernity and the advantages of integrating into these new spaces. Of this dynamic, the main agent is the State (in the Western Amazon), in addition to the participation of property developers in advertising.
\end{abstract}

Keywords: Metropolitan space; Manaus Metropolitan Region; Semiotics.

\section{INTRODUÇÃO}

O estudo da semiótica é a observação dos signos e dos significantes, sendo fundamental aos estudiosos da linguagem (ECO, 2000; SANTAELLA, 1998). A linguagem, certamente, é o mais importante artifício dominado/criado pela humanidade, sendo instrumento de passagem de todo tipo de informação, o que levou 
aos princípios civilizatórios e estes, por sua vez, ao desenvolvimento das sociedades até a contemporaneidade.

Em termos introdutórios, a semiótica considera a semiose como conceito-chave e presume a significação. A semiose é entendida como um sinal somado a uma interpretação, sendo que o produto do processo são os "signos". Considera-se também a característica generalizadora da significação. Isto é, conforme Whalterbense (2000 apud FERNANDES, 2011, p. 161), "não existe, em nenhuma atividade espiritual, um meio utilizável ou utilizado que, uma vez referido a qualquer fato ou acontecimento material, ou não material, não pertença à teoria geral dos signos".

A significação, portanto, é intrínseca à relação antropológica, mas que também pode se especializar, tornando-se, neste caso, geográfica. Não somente do ser humano frente ao ser humano, mas também do homem se confrontando com meio. Assim, tanto os processos sociais como os naturais - uma vez interpretados pelo crivo do intelecto humano - tem significação, seja intencionalmente ou não. Define-se o sistema de significação como aquele que une entidades presentes e unidades ausentes, o que na perspectiva filosófico-peirceana significa algo material (presente) estando para qualquer outra coisa (ausente). Ou seja, a significação requer a presença de um código e, a partir da instância social, podemos falar de um sistema de significação (ECO, 2000).

Autores como o geógrafo Milton Santos instrumentalizam - tangencialmente ou diretamente — os "signos" em suas análises. É em uma de suas principais obras A Natureza do Espaço - que o autor sustenta a proposta interpretativa sobre o espaço geográfico constituir um sistema de objetos indissociável de um sistema de ações. Segundo Santos (2006, p. 41), os objetos são "aquilo que o homem utiliza em sua vida cotidiana, ultrapassa o quadro doméstico e, aparecendo como utensílio, também constitui um símbolo, um signo". O autor utiliza a semiótica para traduzir a substância simbólica da materialidade do espaço (objetos).

Como exemplo, o autor define o automóvel como um dos principais signos da condição contemporânea, sendo que "o automóvel é [...] um dos mais importantes signos de nosso tempo e seu papel de produção do imaginário tem profunda repercussão sobre o conjunto da vida do homem, incluindo a redefinição da sociedade e do espaço (SANTOS, 2006, p. 41). Ele ainda considera a importância do signo para representar a forma de organização espacial da sociedade atual, pois "as cidades não seriam hoje o que elas são se o automóvel não existisse" (SANTOS, 2006, p. 41). Nesse sentido, o desenho urbanístico das metrópoles, a partir do automóvel, é produzido essencialmente em função deste.

A hipótese que fundamenta esta reflexão versa sobre uma experiência interpretativa quanto à relação da semiótica com os processos espaciais da Região Metropolitana de Manaus (RMM) enquanto um recorte da instância social. A ênfase é dada na metropolização do espaço e sua complexidade sígnica dos objetos produzidos pelos agentes modeladores do espaço urbano na produção de um processo de metropolização induzida no contexto da região.

Neste trabalho, a análise recai sobre o recorte espacial da RMM localizada na Amazônia Ocidental. A reflexão é sobre o processo de metropolização do espaço que, 
conforme Sousa (2013) e Lima (2014), efetiva-se com sua institucionalização no ano de 2007 e com o Plano Diretor Integrado da Região Metropolitana de Manaus (PDIRMM). Assim, objetiva-se compreender a metropolização do espaço e seus signos a partir da semiótica no contexto da RMM. Nesse sentido, pretende-se: a) Indicar o processo de metropolização induzida; b) Entender como o processo de metropolização articula e produz um discurso legitimador sobre os objetos; c) Interpretar, a partir do estudo da semiótica, sua importância na compreensão do processo de metropolização, considerando a Ponte Jornalista Phelippe Daou e da Cidade Universitária da Universidade Estadual do Amazonas (UEA).

\section{PROCEDIMENTOS METODOLÓGICOS}

Foi realizado o levantamento bibliográfico sobre a temática abordada. Consultou-se banco de teses, dissertações, artigos científicos e literaturas de base conceitual, objetivando o aprofundamento dos conceitos trabalhados. Destacamos os esforços da interpretação sobre a teoria da semiótica e suas relações com a teoria da Geografia, visto que os signos corroboram na imagética, discurso e produção do espaço geográfico.

Elaborou-se a construção de entendimento entre a semiótica e o conceito de metropolização do espaço, associando à hipótese de uma metropolização induzida, cujo reflexo inicial reside na utilização da propaganda que se faz sobre os lugares.

Foram também realizadas pesquisas de campo na RMM com a finalidade de conhecer os objetos que contribuem para legitimar o processo de metropolização do espaço e que podem ser interpretados como principais signos da dinâmica.

\section{RESULTADO E DISCUSSÕES}

\section{Metropolização induzida na Amazônia Ocidental: alguns pontos iniciais}

Compreender o processo de metropolização enquanto reflexo espacial é relevante uma vez que significa a concepção de uma metamorfose no espaço geográfico (LENCIONI, 2012, 2017), pois interfere modificando a paisagem, mas, principalmente, refere-se às mudanças nos hábitos e na cultura das sociedades. No contexto da RMM isto não é diferente.

Entretanto a metropolização do espaço não se verifica na totalidade, no que se refere à sua expressão socioespacial, visto que, empiricamente, a RMM não se adequa aos princípios norteadores utilizados para se pensar as regiões metropolitanas brasileiras instituídas a partir de 1973, tais como adensamento, contiguidade de espaços produzidos e conurbação. Apesar disso, conforme Lencioni (2012), a metropolização é dada como um reflexo da globalização, esta é a força que leva à homogeneização global, portanto, a metropolização do espaço é a tendência de nivelamento espacial a partir da metrópole, consagrando-se, não somente, mas também com a conurbação e intensificação dos fluxos de pessoas e mercadorias. Apesar da RMM não apresentar conurbação - que, por sinal, está sendo produzida entre a metrópole Manaus e o 
município de Iranduba (SOUSA e LIMA, 2020) - há uma intensificação de fluxos demonstrada por Ehnert (2011). Dessa forma, verifica-se a metropolização do espaço dada pelas estruturas estabelecidas pelo Estado e o discurso de modernidade daí resultante (LIMA, 2014; BERNARDINO, 2019).

Desse modo, o marco principal deste processo, primeiramente, é a institucionalização da RMM, isto é, a sua dimensão jurídica, definidora de um território que passa a ser metropolitano, ainda que não metropolizado em sua maior parte, sendo intensificado com a Ponte Jornalista Phelippe Daou, que se apresentou como meio do rompimento da descontinuidade espacial e como um indutor da metropolização a partir metrópole Manaus em direção ao município de Iranduba. Sobre isso, Sousa (2013) defende a influência determinante do capital na modelação do espaço, na metropolização da RMM e na construção da Ponte. Para o autor, há a demanda de agentes do capital que procuram se territorializar para além da atual metrópole, onde se vislumbra potencial exploratório. Ou seja, ocorre um processo de adequação das estruturas produzidas, como na produção de objetos pelos agentes modeladores.

Todavia, o capital sozinho não poderia causar as mudanças sem as estruturas e combinações que modelam o espaço e o território. Isto é, os lugares, permitindo que esse capital se estabeleça juntamente dos novos agentes modeladores do espaço, avaliam as transformações e as viabilizam ou não. Então, a Ponte Jornalista Phelippe Daou não é somente um marco arquitetônico, mas também um marco simbólico de interesse de integração das cidades da RMM, fato que será abordado com maior ênfase posteriormente.

Manaus, a metrópole da Amazônia Ocidental figura como o núcleo urbano mais populoso e importante da região. Como metrópole regional, desempenha um papel primordial, enfocando a globalização na região. Constata-se essa importância por conta da institucionalização da RMM. Apesar disso, segundo Conceição (2016), tratase da região metropolitana brasileira com menor densidade demográfica. Percebe-se que, no nível territorial há uma dimensão superlativa, mas no nível demográfico nem tanto.

A partir da Lei Complementar no 52, de 30 de maio de 2007, a RMM é instituída com sete municípios: Manaus, Iranduba, Careiro da Várzea, Novo Airão, Presidente Figueiredo, Rio Preto da Eva e Itacoatiara; e, mais um, com a Lei Complementar no 59, de 27 de dezembro de 2007 onde é incluído o município de Manacapuru. A institucionalização permitiria o direito ao recebimento de repasse financeiro exclusivo para regiões metropolitanas, bem como o planejamento através do Plano Diretor Integrado da Região Metropolitana de Manaus. A partir da Lei Complementar $\mathrm{N}^{\circ}$ 64/2009, foram adicionados mais cinco municípios: Careiro, Autazes, Silves, Itapiranga e Manaquiri, totalizando 13 municipalidades (Figura 01). 

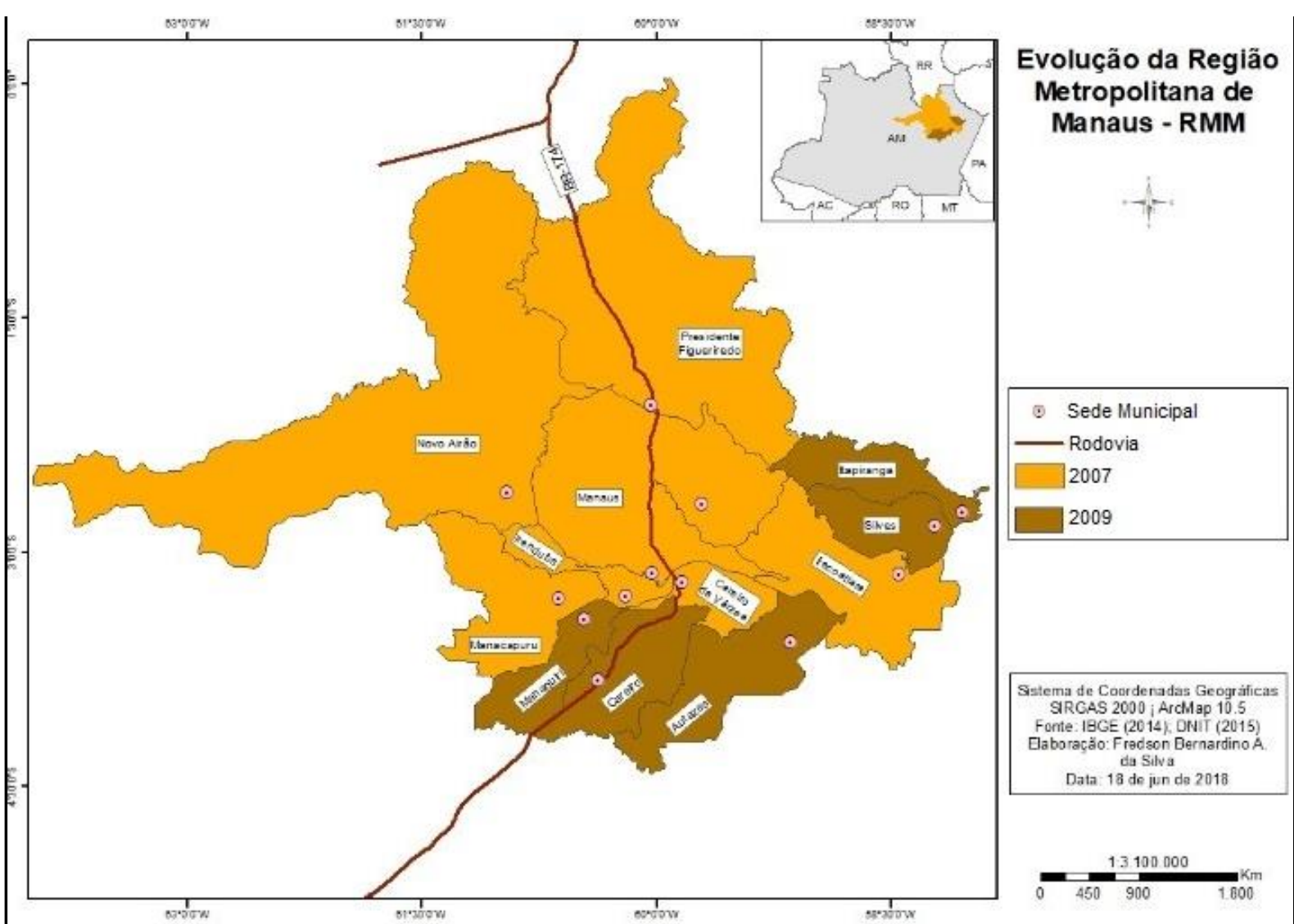

Figura 01. Mapa da Evolução da RMM. Org: Autores, 2019.

Nessa perspectiva, a RMM em sua dimensão jurídica, pressupõe a síntese concreta de possibilidades de se induzir ao processo de metropolização, ou seja, a indução em uma síntese espacial que agrega várias dimensões. Nesse sentido, conforme Lima (2014), a institucionalização da RMM, estabeleceu as bases para a indução do processo de metropolização do espaço na região tendo o Estado como o principal agente modelador. Caracteriza-se, portanto, a partir das análises do autor uma categoria analítica, qual seja, a "metropolização induzida".

Dessa forma a metropolização é compreendida como uma fase posterior ao processo de urbanização, possibilitando novas condições de produção e reprodução do espaço, bem como à gestão do território o que leva às novas significações ao espaço e a novos arranjos espaciais.

Historicamente podem ser apontados como principais aspectos de entendimento do processo de metropolização do espaço em sua forma clássica de análise, a aglomeração e a contiguidade de múltiplos núcleos urbanos municipais. Nesta lógica, a institucionalização (dimensão jurídica) de uma região metropolitana viria para legitimar ou normatizar a realidade socioespacializada. Porém, os pressupostos da metropolização clássica, em alguns aspectos, não correspondem ao quadro que se apresenta no caso da RMM, cuja legitimação, ao contrário das demais, veio primeiramente pela dimensão jurídica e ainda vislumbra uma consolidação socioespacial de forma mais materializada. 
A dimensão política, nesse ponto, ganha destaque por ser aquela que promove as mudanças e ações na dimensão espacial e ao mesmo tempo se articulando à dimensão jurídica, nos limites político-administrativos por ela legitimados que caracteriza a metropolização induzida. No caso da RMM, marcando a divergência interpretativa em relação às interpretações então clássicas sobre a metropolização do espaço das quais não consideravam com tamanha relevância a participação do Estado como indutor, pois este afirmava de forma institucional o que historicamente já havia sido produzido no espaço geográfico. No que se refere à RMM, o Estado, por meio do Governo do Estado do Amazonas, constitui, ao lado de proprietários fundiários e promotores imobiliários, o agente modelador desse processo, induzindo à metropolização do espaço na Amazônia Ocidental (LIMA, 2014).

\section{O discurso e o contexto da urbanização em Manaus}

Ao se aplicar a estrutura da semiótica, procura-se, aqui, elucidar as significações quanto aos elementos que compõem a metropolização. A contribuição para o entendimento da metropolização do espaço parte do que entendemos como a fração do processo que é refletido na propaganda, procurando verificar que as mudanças e conflitos delas resultantes são projeções de discursos que trazem elementos como um "apontamento para o futuro metropolitano" e uma forma de "inserção na modernidade".

Destaca-se que o processo de metropolização do espaço no contexto da Amazônia Ocidental possui singularidades que influenciam em sua produção. Ressalta-se também as particularidades do padrão de urbanização na Amazônia Ocidental, onde um breve olhar sobre o Ciclo da Borracha, as políticas territoriais no Regime Militar, bem como na Zona Franca de Manaus pontuam algumas das influências de um tipo de urbanização altamente concentrada e centralizada na capital do Estado do Amazonas (BERNARDINO, 2019). Em cada fato abordado no território não se desassocia de um discurso legitimador específico que revela um caminho na dimensão ideológica.

No auge do Ciclo da Borracha (1879-1912), produziu-se em Manaus um discurso de "embelezamento" da cidade, cujo o resultado foi uma política de normatização e regulação das fachadas dos prédios, fruto da ideologia da Belle Époque. Aqueles que não seguiram tal uniformização tiveram que se deslocar para áreas mais periféricas da cidade (MESQUITA, 2006).

Posteriormente, com a institucionalização da Zona Franca de Manaus, o discurso é de "desenvolvimento industrial para a região", com a ideologia desenvolvimentista dos governos militares. O discurso utilizado foi de crescimento econômico e integração nacional (NOGUEIRA e OLIVEIRA NETO, 2015). A partir desse período, Manaus experimenta um crescimento demográfico exponencial, abrindo caminho que levaria Manaus à condição de "metrópole regional" (IBGE, 2007). Nesse sentido, o direcionamento do discurso por parte do Estado à sociedade pode ser considerado como de exaltação dos benefícios de ser inserido num circuito global de produção e serviços. 
Assim, o "discurso" aparece como legitimador das propostas e interações dos agentes modeladores do espaço que compõem a instância social (BERNARDINO, 2019). E, nesta perspectiva, entende-se que essa dinâmica é reproduzida no que se relaciona à metropolização do espaço que ocorre na RMM por meio da produção de objetos, aqui analisados como signos.

\section{Discurso da metropolização induzida e produção de signos}

A metropolização induzida que ocorre no eixo entre a metrópole Manaus e o município de Iranduba apresenta três principais agentes modeladores, articulados entre si: o Estado, os promotores imobiliários e os proprietários fundiários. Isto pode ser observado no Plano Diretor Integrado da RMM (PDIRMM), pois:

\section{A Região Metropolitana de Manaus (RMM) é um desafio extraordinário a nos inspirar, de magna importância para o desenvolvimento estratégico do Estado do Amazonas, a partir de sua capital, por reunir todas as condições em ser reconhecida, como metrópole da sustentabilidade, em ambiente de floresta tropical [...] (PDIRMM, 2010, p. 2 apud LIMA, 2014, p. 137).}

Ao suscitar a "sustentabilidade", no Plano Diretor Metropolitano, o Estado indica uma estratégia dos promotores imobiliários que produzem um "discurso ambientalista", uma "apologia à natureza, ao verde" (LENCIONI, 2011, p. 190) voltado a superficialidade estética sob finalidade de valorização do espaço (LIMA, 2014).

Essa vinculação, especialmente, entre esses três agentes modeladores pode ser explicada, pois, segundo Carvalho (2011), o processo de metropolização suscita uma galopante especulação imobiliária nas áreas que estão em destaque para o crescimento da metrópole e que pode ser intensificado por áreas que concentrem amenidades como o fácil "acesso ao verde". O que também pode confirmar, de acordo com Corrêa (2003), a função dos promotores imobiliários no meio urbano, atuando como direcionadores dos processos de crescimento, principalmente, horizontal das cidades.

Como já exposto, a característica principal da metropolização do espaço é a formação de um novo paradigma socioespacial nos lugares e nos modos de vida. No caso da metrópole Manaus, verifica-se uma indução desse processo coordenada pela intervenção do Governo do Estado do Amazonas em articulação com os promotores imobiliários que é legitimada pela institucionalização da RMM no ano de 2007 e que produz objetos e símbolos que evocam ideologicamente a "modernidade".

Não obstante, quanto ao âmbito do espaço vivido na metropolização do espaço, Ferreira (2014, p. 13) aponta o cotidiano como indicador espacial, "embora muitas vezes banalizado, já que se expressa por sua miséria e riqueza a partir de eventos triviais, caracteriza-se como a mediação entre a repetição e a criação". Fala-se de uma parcela referente à experienciação das espacialidades a qual está sujeita aos discursos e as ações oriundas de distintos vetores, como o vulnerável grupo dos socialmente excluídos (CORRÊA, 2003).

Essa perspectiva pode ser aprofundada através do estudo de caso do signos relativos à metropolização induzida que, conforme nossa hipótese, são objetos que, no plano 
da linguagem, pretendem associar a produção do espaço metropolitano às amenidades em diversas dimensões das instâncias natural e social ${ }^{1}$. Como consequência, a metropolização investigada enquanto detentora de singularidades apresenta dois principais signos-empreendimentos que marcam tal processo: a Ponte Jornalista Phelippe Daou e a Cidade Universitária da Universidade Estadual do Amazonas.

\section{A Ponte Jornalista Phelippe Daou: um signo de integração regional}

Possuindo 3,595m de extensão, mais conhecida como Ponte (do) Rio Negro, a Ponte Jornalista Phelippe Daou, do tipo estaiada, foi inaugurada no dia 24 de outubro de 2011 e funciona como a conexão direta entre a metrópole Manaus e o município de Iranduba, mas também permitindo a conexão indireta com os municípios de Manacapuru e Novo Airão.

No início da Ponte, do lado da metrópole, é possível observar um enunciado do Estado que relaciona a "conquista" pela proposta que a Ponte simboliza. Ao lado, o discurso é da emergência de novas oportunidades que somente a Ponte poderia fornecer (Figura 02).

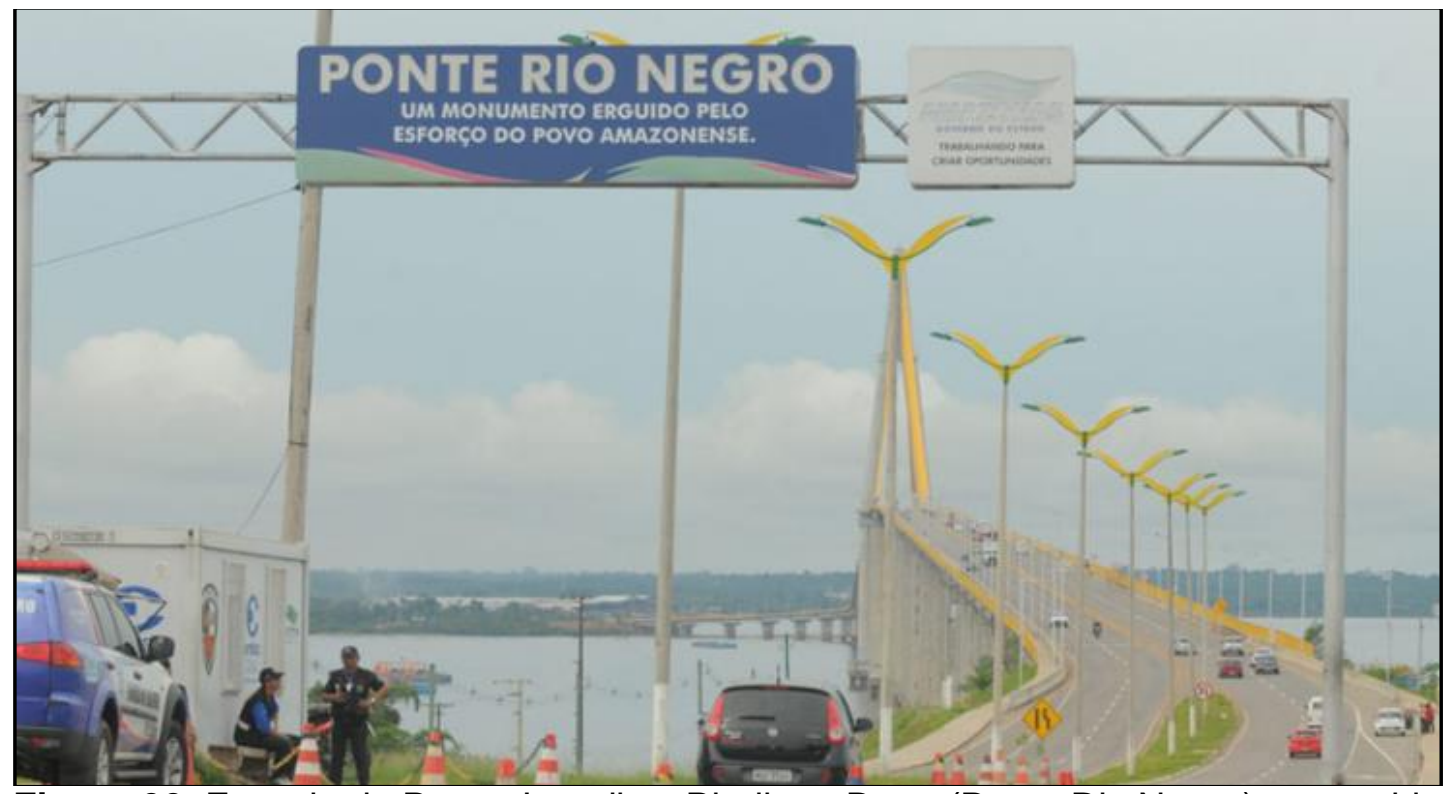

Figura 02. Entrada da Ponte Jornalista Phelippe Daou (Ponte Rio Negro) no sentido Manaus-Iranduba. Fonte: A CRÍTICA (2017).

Nesse sentido, a Ponte marca a necessidade de uma continuidade do deslocamento terrestre, ao mesmo tempo em que rompe a descontinuidade espacial, ou seja, verifica-se uma opção pelo rodoviarismo, reproduzindo nessa parte da Amazônia o que é o modelo predominante no restante do Brasil. A forma anterior de conexão entre

1 Considera-se as várias dimensões da vida social: política, econômica e etc. Também natural, dada a apropriação de vários elementos da natureza com a finalidade à valorização do espaço, como a "precificação do verde". 
a metrópole Manaus e o município de Iranduba era realizada com o uso de balsas num tempo de trajeto bem maior. Para Sousa (2013, p. 119-120), esse objeto desencadeia uma transformação no crescimento de fluxo na quantidade de veículos, nos horários de trânsito e, principalmente, na "noção de distância entre os lugares expressa pelo tempo de deslocamento".

Todavia, é importante pontuar que as possibilidades e o potencial de exploração do modal hidroviário, numa perspectiva multimodal, é olvidado pelo menos parcialmente, tendo em vista a geomorfologia da região, composta por densa rede hidrográfica (BUENO et al., 2014). Em detrimento disto, é reforçado o automóvel como um signo urbanístico, muito relacionado à dinâmica das grandes cidades (SANTOS, 2006). Essa questão possui, portanto, uma dimensão ideológica, produzindo um discurso pautado nos tempos rápidos, na circulação de mercadorias e no automóvel particular de passeio, rompendo com a descontinuidade que o Rio Negro provocava.

Dessa forma, conforme sustenta Maricato (2008), o carro moldou as cidades e a indústria automobilística tem grande participação na expansão e nos urbanismos em geral das cidades, tornando-se um elemento típico da urbanidade. O que converge com o pensamento de Corrêa (2003), que define o espaço urbano como uma conjuntura social, ou seja, um reprodutor das relações de produção e ideias, onde a indústria, através dos grandes proprietários dos meios de produção influencia, consome e remodela o espaço. Em suma, o Estado realiza por meio da Ponte seu objetivo de integração regional, não sem gerar conflitos de espacialidades (Figura 03).

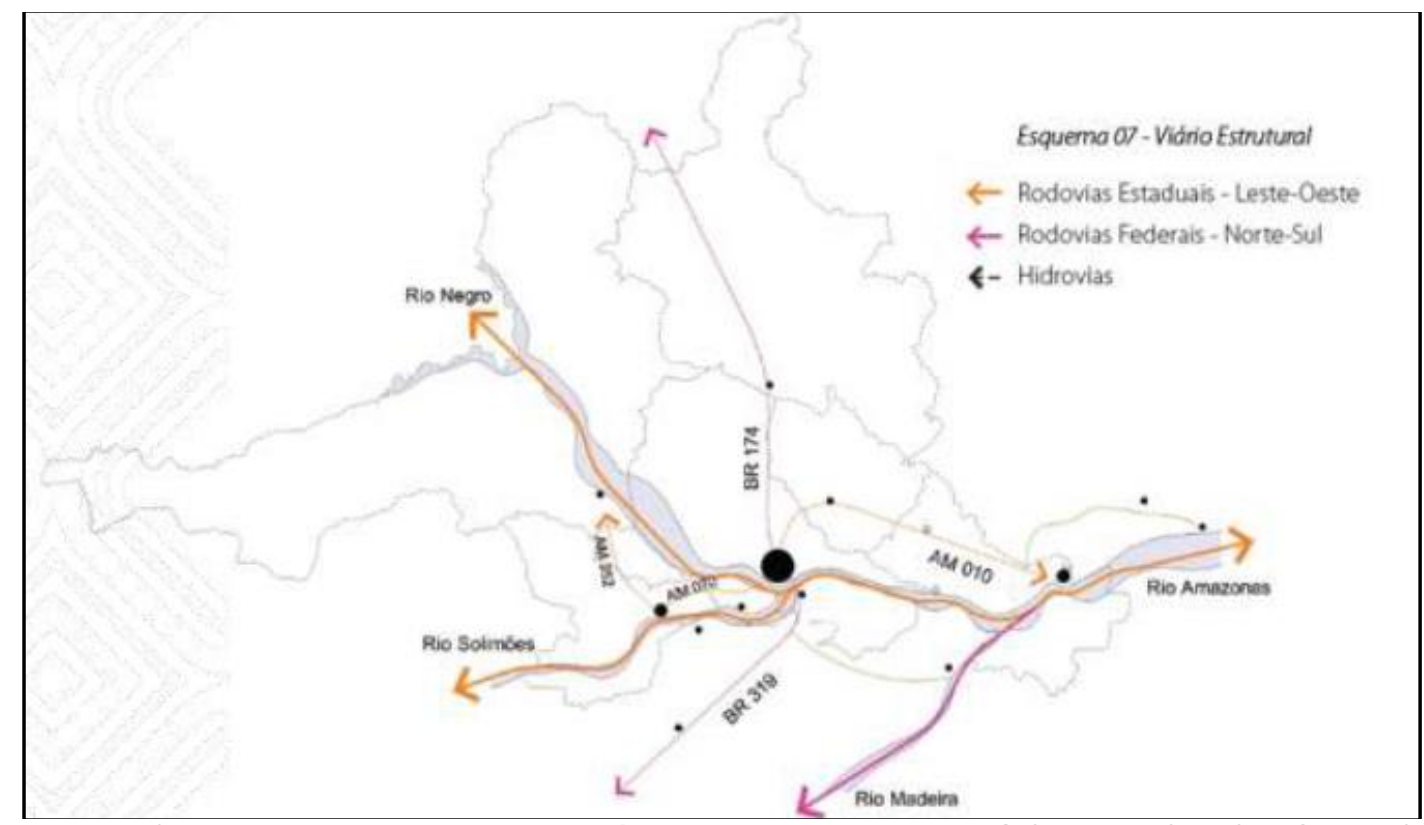

Figura 03. Cartograma do Esquema viário estrutural. Fonte: GOVERNO DO ESTADO DO AMAZONAS (2010a).

Essa proposta de integração apresenta uma rede urbana tendo a metrópole Manaus como principal nó, os demais fixos estão organizados em eixos de fluxo rodofluvial. No eixo norte-sul, tem-se as rodovias federais. No eixo leste-oeste, tem-se as rodovias estaduais. $O$ vetor de maior dinamização do atual processo de metropolização 
induzida ocorre na "borda sul" com ligação pela rodovia AM-070, vetor onde se encontra a Ponte.

Sobre a dinamização da região pelo Estado, Sousa (2013, p. 236) considera que são "denominadas de políticas públicas, e se manifestam em obras de infraestrutura, como abertura de estradas e a instalação de serviços públicos", apesar disso, constata-se a tendência de satisfazer as demandas de segmentos distintos como proprietários fundiários, promotores imobiliários e o próprio Estado, tendo como discurso produzido um "desenvolvimento regional". O que fica claro são as práticas espaciais do Estado num processo de indução à metropolização do espaço no contexto da RMM, essa intervenção teria desdobramentos em várias amenidades (GOVERNO DO ESTADO DO AMAZONAS, 2010b), pois:

\footnotetext{
Abre a possibilidade de captação de recursos para obras dos setores público e privado, como infraestrutura, transporte, saúde, educação, segurança, dentre outras. O início da operação da Ponte sobre o Rio Negro facilitará não só a integração rodoviária metropolitana e intrarregional, como também da Região Metropolitana com o restante do país, e com os países da América Latina (GOVERNO DO ESTADO DO AMAZONAS, 2010b).
}

Dessa forma, o significante referente a Ponte Jornalista Phelippe diz respeito ao atendimento de demandas e produção de objetos econômicos e sociais. Trata-se de um objeto geográfico e arquitetônico que, segundo a citação acima, visa a integração regional, nacional e internacional. Trata-se, dentro da concepção sígnica espacial proposta por Ruy Moreira (1993, p. 46-50 apud BERTOL, 2017, p. 69) de uma "percepção espacial e da antropologia da imagem", onde "a imagem deixa de ser o puro reflexo das formas do mundo objetivo e passa a ser subjetividade histórica que culturalmente se basta e se explica". O que, para a Ponte, também dá ao objeto um caráter de "conquista".

\section{A Cidade da UEA: um signo da nova centralidade na RMM}

Outro objeto que leva a interpretação de uma indução à metropolização é o empreendimento estatal da 'Cidade Universitária' da Universidade do Estado do Amazonas (UEA). Sobre as obras, o zoneamento foi realizado no município de Iranduba, limítrofe à metrópole e conectado pela Ponte Jornalista Phelippe Daou. A propaganda consta de um progresso e ascensão de um objeto com função de centro educacional e científico, antes, somente encontrado em Manaus. O empreendimento foi previsto para o início de 2014. Entretanto, as obras não tiveram grande avanço e, ainda em 2020, não se vislumbrava a continuidade e conclusão de sua obra (Figura 04). 


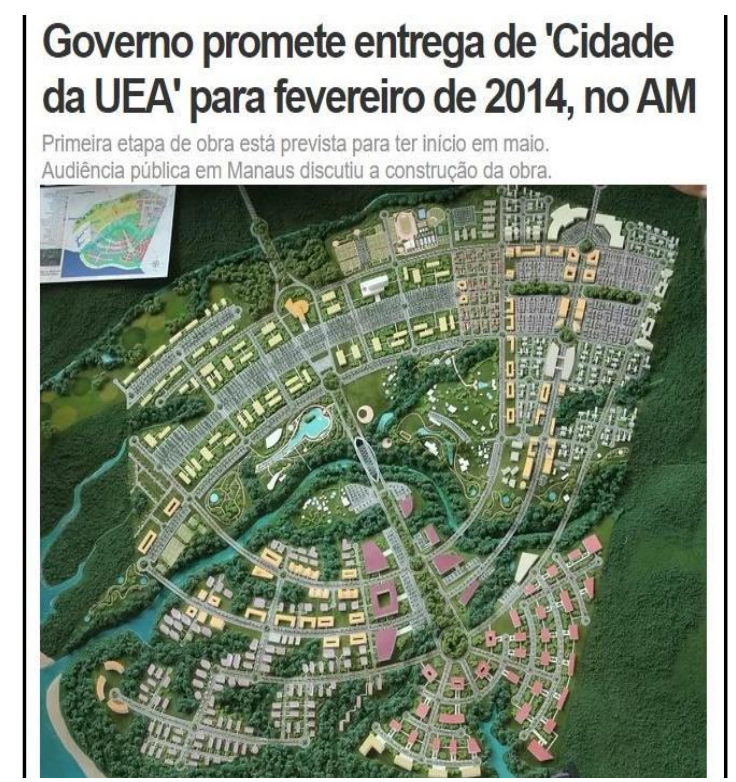

Figura 04. Projeto da Cidade da UEA. Fonte: G1 Amazonas (2013). Org.: Autores, 2018.

Segundo o Relatório de Gestão da UEA, uma das e possivelmente a principal intenção da Unidade Gestora do Projeto com o empreendimento é de funcionar como desencadeador, atraindo instituições nacionais e internacionais voltadas para região nos seguimentos de ensino superior, da atividade universitária e de pesquisa, muito embora a principal consumidora da infraestrutura seria a própria UEA (GOVERNO DO ESTADO DO AMAZONAS, 2013). Então, ao idealizar o projeto, o Estado pretende promover um novo centro acadêmico-universitário e de produção voltado ao conhecimento, à pesquisa e à mão de obra mais qualificada no município de Iranduba induzindo a um nivelamento com a metrópole, tendo desdobramentos na dinamização da ampliação do setor imobiliário e de serviços. Isto constitui, portanto, uma indução ao processo de metropolização do espaço para a região.

O montante inicial destinado foi de $R \$ 55.000 .000,00$. A primeira etapa do empreendimento está orçada em $R \$ 150.500 .000,00$ para atender uma comunidade universitária de cerca de 20 mil membros (G1 AMAZONAS, 2013). Todavia, o que se tem até o presente é o início de um zoneamento e fundação de alguns prédios, estando longe de atender às funções que a propaganda pretendeu (Figura 05). 


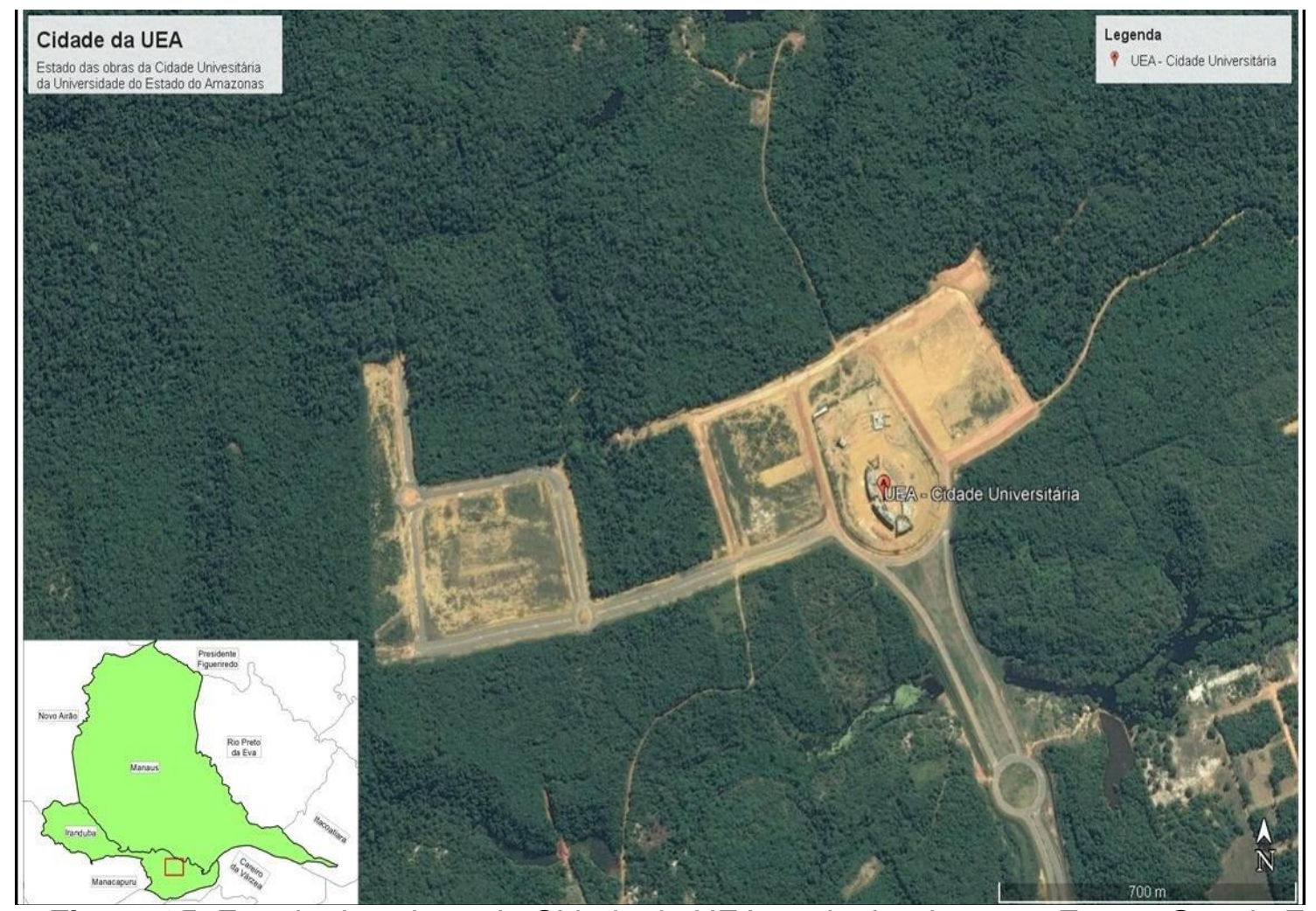

Figura 05. Estado das obras da Cidade da UEA em junho de 2017. Fonte: Google Earth (2018), CNES/Airbus (2018). Org.: Autores, 2019.

Desse modo, a proposta de um empreendimento com tais dimensões pretende contribuir para a formação de profissionais, fundando um polo educacional e científico. Neste caso, a função sígnica sobre a prática espacial do Estado está direcionada à dinamização de fluxos (pessoas, mercadorias, informações), objetivando uma promoção de "planejamento", "modernidade" e "integração", além da construção de uma imagética da educação superior como uma das prioridades na governança.

Além do Estado, para os agentes modeladores como os promotores imobiliários, a Cidade da UEA constitui um objeto de valorização do espaço do seu entorno, pois é incorporada na publicidade sendo "vendida" juntamente aos loteamentos e imóveis, conforme pode ser observado no exemplo do quadro abaixo (Quadro 01). 
Quadro 01. Cidade Universitária instrumentalizada pelos promotores imobiliários.

\begin{tabular}{|c|c|c|c|}
\hline \multicolumn{4}{|c|}{ 쇼 Informaçōes do imóvel } \\
\hline \multirow{2}{*}{$\begin{array}{l}\text { Tipo de } \\
\text { imóvel }\end{array}$} & \multirow[t]{2}{*}{ Apartamento } & Andar & $1^{\circ}$ Andar \\
\hline & & Dormitórios & 2 \\
\hline Código & 232 & Banheiros & 1 \\
\hline Endereço & AM 070 & Vagas & 1 \\
\hline Numero & $8, \mathrm{~km} \mathrm{9}$ & Área privativa & $53 \mathrm{~m}^{2}$ \\
\hline Bairro & Iranduba & Área total & $64 \mathrm{~m}^{2}$ \\
\hline $\begin{array}{l}\text { Ponto de } \\
\text { referência }\end{array}$ & $\begin{array}{l}\text { A um kilometro da cidade } \\
\text { universitaria da UEA }\end{array}$ & Idade do imóvel & 5 anos (2015) \\
\hline Cidade & Iranduba & Estuda permuta & Sim \\
\hline Transação & Venda, Locação, Lançamento & Aceita financiamento & Sim \\
\hline Finalidade & Residencial & & \\
\hline
\end{tabular}

Fonte: CIM (2020).

Os promotores imobiliários também contribuem para a construção sígnica da Cidade da UEA. A lógica praticada é de associar os empreendimentos imobiliários com as potenciais amenidades do morar próximo de uma área futuramente dinamizada e qualificada como um centro acadêmico-universitário vinculado à modernidade e à associação desse signo, como elemento que pode valorizar os lotes próximos.

Nesse contexto, com o empreendimento desse objeto, procura-se produzir um tipo de centralidade baseada na matriz acadêmica e de produção do conhecimento. $O$ significante que se observa desse tipo de proposta - ou do discurso que se quer associar - é de encaminhamento em direção à modernidade na questão técnica e científica, coadunando com fato de que o processo de metropolização do espaço está associado aos discursos que marcam a periodização da modernidade, bem como da globalização e, portanto, da questão informacional.

\section{AGRADECIMENTO}

Agradecemos ao CNPq pela concessão de bolsa de iniciação científica.

\section{CONSIDERAÇÕES FINAIS}

O processo de metropolização do espaço constitui numa dimensão tanto conceitual quanto real. Neste sentido, a dimensão conceitual nem sempre envolve a todas as características da realidade. No caso da RMM, as trocas e fluxos intensos entre os municípios não ocorrem como na concepção clássica de metropolização adotada no Brasil. Na RMM, o processo de metropolização ocorre predominantemente por influência estatal e, portanto, de forma induzida.

Nesse contexto, os signos constituem forte instrumento ideológico na indução, tendo os agentes modeladores do espaço como aqueles que possibilitam a concretização 
de uma expressão socioespacial metropolitana em espaços antes não metropolizados.

De forma comparativa e visando estudos futuros, no caso da metropolização na Amazônia, pode-se apontar dois principais eixos: Manaus e Belém. Respectivamente, os principais centros das Amazônias Ocidental e Oriental. Apresentando singularidades espaciais em cada eixo, sendo que Belém preencheu os requisitos clássicos do processo de metropolização e Manaus, no entanto, apresenta um padrão em que o discurso precede e intensifica ao próprio processo.

No domínio da dimensão ideológica, o meio de indução aos processos espaciais como a metropolização podem ocorrer de forma significativa. A metropolização induzida é, no caso da RMM, viável através de um discurso articulado pelo Estado, em especial, o governo do Estado do Amazonas. Trata-se de uma força capaz de movimentos que se dão numa psicosfera que preside uma tecnosfera, impactando o território e produzindo novos arranjos espaciais, cuja expressão é a metropolização socioespacializada.

Tanto a Ponte Jornalista Phelippe Daou quanto a Cidade da UEA, bem como o discurso de modernidade, são os objetos e o significante mais relevantes da dinâmica observada que contribuem na indução de se alcançar um status metropolitano em sua expressão espacial na RMM. São signos de um processo que promove transformações e afeta as espacialidades preexistentes, gerando conflitos cuja síntese revela as novas espacialidades oriundas das ações e articulações dos agentes modeladores.

\section{REFERÊNCIAS}

A CRÍTICA. Ponte Rio Negro ganha o nome jornalista Phelippe Daou. 2017. Disponível: $<$ https://www.acritica.com/channels/cotidiano/news/ponte-rio-negro-ganha-o-nome-dojornalista-phelippe-daou>. Acesso em 25 jul. de 2020.

GOVERNO DO ESTADO DO AMAZONAS. Plano Diretor Integrado da Região Metropolitana de Manaus - PDIRMM. Manaus: 2010a.

GOVERNO DO ESTADO DO AMAZONAS. Governador apresenta Plano de Desenvolvimento da Região Metropolitana de Manaus. 2010b. Disponível: $<$ http://www.amazonas.am.gov.br/2010/11/governador-apresenta-plano-dedesenvolvimento-da-regio-metropolitana-de-manaus/>. Acesso em 25 jul. 2020.

GOVERNO DO ESTADO DO AMAZONAS. Relatório de Gestão. Universidade do Estado do Amazonas. Manaus: 2013.

BERTOL, L. R. Fenomenologia, semiótica e geografia da percepção: alternativas para analisar o espaço geográfico. Revista da Casa da Geografia de Sobral, Sobral, v.4\%5, p. 67$79,2002 / 2003$. 
BUENO, M. J. C.; SILVA, G. G. R.; STETTINER, C. F.; MARCELLOS, L. N.; SARDEIRO, F. G. Modal fluvial na Amazônia: desafios e oportunidades. Revista Eletrônica da Faculdade de Ciências Exatas e da Terra, v. 3, n. 5, 2014.

CARVALHO, A. L.. Metropolização e o discurso da modernidade na reposição da periferia: o bairro do Cabuçu no município de Guarulhos. Tese (Doutorado em Geografia Humana). Faculdade de Filosofia, Letras e Ciências Humanas, Universidade de São Paulo. São Paulo: 2011.

CIM - CORRETOR DE IMÓVEIS MANAUS. Novo apartamento em Iranduba - Residencial Bela Vista. 2020.2 Disponível: $<$ https://www.corretordeimoveismanaus.com/232/imoveis/venda-locacao-lancamentoapartamento-2-dormitorios-iranduba-iranduba-am>. Acesso em 05 ago. de 2020.

CORRÊA, R. L. O Espaço Urbano. São Paulo: Ática, 2003.

CONCEIÇÃO, S. G. Amazônia em ontogenia: o caso da Região Metropolitana de Manaus. Tese (Doutorado em Ciências do Ambiente e Sustentabilidade na Amazônia). Universidade Federal do Amazonas. Manaus: 2016.

ECO, U. Tratado Geral da Semiótica. 3 ed. São Paulo: Perspectiva, 2000.

EHNERT, A. R. A Região Metropolitana de Manaus e as migrações pendulares. Dissertação (Mestrado em Geografia Humana). Faculdade de Filosofia, Letras e Ciências Humanas da Universidade de São Paulo. São Paulo: 2011.

FERREIRA, A. Metropolização do Espaço, Tensões e Resistências: Entre Espaços de Controle e Controle do Espaço. Scripta Nova. Universidad de Barcelona. ISSN: 1138-9788. Depósito Legal: B. 21.741-98 Vol. XVIII, núm. 493 (55), 1 de noviembre de 2014. Disponível: $<$ http://www.ub.edu/geocrit/sn/sn-493/493-55.pdf >. Acesso em 20 ago. de 2018.

FERNANDES, J. D. C. Introdução à semiótica. In: ALDRIGUE, A. C. S.; LEITE, J. E. R. (Org.). Linguagens: usos e reflexões. 1. ed. João Pessoa: UFPB, 2011. v.8. Disponível: <http://www.cchla.ufpb.br/>. Acesso em 29 abr. 2018.

G1 AMAZONAS. Governo promete entrega de 'Cidade da UEA' para fevereiro de 2014, no AM. Publicado: 06/02/2013, 08h27 - Atualizado em 06/02/2013, 08h27 Disponível: $<$ http://g1.globo.com/am/amazonas/noticia/2013/02/governo-promete-entrega-de-cidadeda-uea-para-fevereiro-de-2014-no-am.html>. Acesso em 18 de jul. 2018.

IBGE - INSTITUTO BRASILEIRO DE GEOGRAFIA E ESTATÍSTICA. Regiões de Influência das Cidades - REGIC. Rio de Janeiro: 2007.

LENCIONI, S. Condomínios industriais: um novo nicho dos negócios imobiliários. In: Paulo Cesar Xavier Pereira (org.). Negócios imobiliários e transformações sócio-territoriais em cidade da América Latina. São Paulo: FAUUSP, 2011. 
LENCIONI, S. Metropolização do Espaço: processos e dinâmicas. São Paulo, 2012 (mimeo).

LENCIONI, S. Metrópole, metropolização e regionalização. Rio de Janeiro: Consequência, 2017.

LIMA, M. C. Quando o amanhã vem ontem: a institucionalização da Região Metropolitana de Manaus e a indução ao processo de metropolização do espaço na Amazônia Ocidental. Tese (Doutorado em Geografia Humana). Faculdade de Filosofia, Letras e Ciências Humanas da Universidade de São Paulo. São Paulo: 2014.

MARICATO, E. O automóvel e a Cidade. Ciência \& Ambiente. A cultura do Automóvel v.37, p.5-12, 2008. Disponível: <https://erminiamaricato.files.wordpress.com/2012/09/revistaciencia-e-ambiente.pdf>. Acesso em 19 de jul. 2018.

MESQUITA, O. M. Manaus: História e Arquitetura (1852-1910). 3. ed. Manaus: Valer, 2006. NOGUEIRA, R. J. B.; OLIVEIRA NETO, T. Zona franca de Manaus: entre a geopolítica e a geoeconomia. In: I/ Congreso Internacional SETED-ANTE. Seminario Estado, Territorio e Desenvolvemento. O goberno dos territorios. 1-3 de xullo de 2015, Santiago de Compostela, España.

Disponível: $<$ https://www.academia.edu/14445571/Zona franca de Manaus entre a geopolitica e a geoeconomia?auto=download $>$. Acesso em 20 de jul. 2018.

SANTAELLA, L. O que é semiótica. 14 reimp. Col. Primeiros Passos. São Paulo: Brasiliense, 1998.

SANTOS, M. A Natureza do Espaço. Técnica e Tempo. Razão e Emoção. 4. ed. 2. reimp. Col. Milton Santos. São Paulo: Edusp, 2006.

BERNARDINO, F. A. S. Metropolização do espaço na Amazônia Ocidental: discurso no contexto da Região Metropolitana de Manaus. Anais do XIII ENANPEGE, São Paulo, 2019.2 Disponível: $<$ https://www.enanpege2019.anpege.ggf.br/resources/anais/8/1562523770 ARQUIV O ENANPEGE discurso RMM1.pdf>. Acesso em 18 fev. 2020.

SOUSA, I. S. A ponte Rio Negro e a Região Metropolitana de Manaus: adequações no espaço urbano-regional à reprodução do capital. Tese (Doutorado em Geografia Humana). Faculdade de Filosofia, Letras e Ciências Humanas da Universidade de São Paulo. São Paulo: 2013.

SOUSA, I. S.; LIMA, S. P. M. Materializações no espaço urbano-regional da Região Metropolitana de Manaus. Brazilian Journal of Development (BJD), v. 6, p. 1178-1187, 2020. 